\title{
FORMAÇÃo E ATUAÇÃo DO PROFISSIONAL EM EDUCAÇÃO FÍSICA ESCOLAR
}

\author{
José Guilmar MARIZ DE OLIVEIRA*
}

Inicialmente, pediria um pouco de paciência para alguns colegas que têm acompanhado este meu trabalho sobre "formação e atuação do profissional em educação física escolar", em especial a própria Vera e ao Wagner, componentes desta mesa redonda. Pois, talvez se nós traçássemos um esboço de nossas falas de hoje, cada um de nós saberia por onde o outro vai trilhar em sua exposição. Mas, eu vejo que neste momento, talvez. pecar pela repetição seja melhor que pecar pela omissão. Então, tentarei trazer para vocês, neste momento de reflexão, os principais problemas que estamos enfrentando ou encontrando na implementação de uma reforma curricular de preparação profissional, ou seja, na preparação do professor de Educação Física. Ontem, ficou bastante claro, em várias falas, as críticas a esse professor que está atuando hoje nas escolas de primeiro e segundo graus. Como fiz. na conferência inaugural, deixarei claro que entendo muito bem os problemas que as universidades ou as instituições isoladas enfrentam atualmente. Desde o problema da divisão de poder, interferência do governo nas federais, nas estaduais, o problema de verba das particulares, até essa tentativa de menosprezar a universidade ou solicitar-lhe que mostre a sua competência. Também tenho claro os probiemas das greves de professores e funcionários, e esta exposição os leva em consideração; no entanto, não tratarei desses problemas aqui nesta mesa redonda.

A Escola de Educação Física da Universidade de São Paulo, através de debates e discussões com seus professores e alunos, em uma decisão não unânime, mas de $51 \%$ contra $49 \%$, chegou a uma posição: a partir de uma certa data (1992), estaria oferecendo 3 cursos de preparação profissional - o Bacharelado em Educação Física, devido à abertura que a legislação hoje nos dá, a reformulação da Licenciatura em Educação Física, e o Bacharelado em Esporte. Sobre esta habilitação específica, relacionada com o Esporte, não irei tecer maiores comentários, porque foge do escopo deste seminário. Inclusive este Bacharelado em Esporte não está contemplado na atual lcgislação. Mas a Universidade de São Paulo, dentro da sua autonomia universitária, que a própria legislação reforça, estará oferecendo o referido curso. Uma outra posição bem definida que esta Escola de Educação Física da Universidade de São Paulo tem em função desses cursos e que reflete também no curso de preparação profissional do professor de Educação Física, é uma clara distinção entre Educação Física e Esporte, caracterizada pelo próprio oferecimento de dois cursos diferenciados.

Então, gostaria, rapidamente, de mostrar as evidências que existem ou que sempre existiram com referência a esta diferenciação dos dois fenômenos culturais ou das duas práticas sociais distintas. Estou me empenhando agora em uma pesquisa de natureza histórica, para tentar estabelecer quando, ou em que momento, nós, da área da Educação Física passamos a incorporar aqueles dois fenômenos como sinônimos - quero dizer, nós da área relacionada com a formação profissional em Educação Física. Temos evidências claras da diferenciação entre Educação Física e Esporte; evidências, desde tentativas de descrever aquilo que os gregos e romanos faziam com relação a "Educação Física" e "Esporte" entre aspas. Vamos encontrar nítidos momentos de diferenciação destes dois envolvimentos da sociedade grega e da sociedade romana. Apresento também uma evidência mais próxima e contemporânea: Uma posição do Conselho Federal da Educação, dcixa, para muitos que querem enxergar, bem clara esta distinção. $\mathbf{O}$ referido Conselho, em 1977, coloca que no ensino de segundo grau algumas habilitações poderiam

*Escola de Educação Física da Universidade de São Paulo. 
acontecer, inclusive a de professor de Educação Física e do técnico em Esporte. Tenho claro neste momento que, se o Governo, se o Conselho Federal define isso, significa que ser professor de Educação Física é uma coisa, e ser técnico em Esporte é outra; e estas duas coisas ocorrem a nível de segundo grau, e uma não exclui a outra.

Saindo um pouco do âmbito brasileiro, apresento uma colocação interessante de um professor holandês radicado nos Estados Unidos; o professor Broekhoff, em 1970, registrou em um de seus artigos sobre filosofia da Educação Física e do Esporte, ao referir-se à atuação do professor de Educação Física na escola, que " o que quer que seja Educação Física, Esporte é que não é ". A palavra em inglês "Athletics" pode ser entendida como sinônimo de Esporte, e utilizada no sentido de competição esportiva que ocorre entre escolares ou entre universitários. Assim, ele defende que Educação Física e Esporte são coisas distintas apresentando argumentação para tal.

Uma outra evidência é apontada por Cagigal, autor espanhol, que traz em um dos seus trabalhos, em 1966, uma idéia bastante clara quando ele tenta fazer relações entre jogo, esporte, educação física, e educação. Na colocação do professor Cagigal, fica evidente que "educación física" $\epsilon$ uma coisa e "deporte" é outra, existindo algo em comum entre estas duas manifestações, estas duas áreas de estudos, estas duas práticas sociais.

Mais recentemente, em 1987, um periódico muito importante na área internacional, até então denominado Jornal de Psicologia do Esporte, entendeu, numa demonstração da restrição do termo esporte, que o nome do periódico estava inadequado: "esporte" por si so não estaria contemplando alguma outra coisa chamada "exercício". O periódico traz. esta discussão no editorial e de forma proposital alguém diz que, no título do periódico precisa aparecer, além da palavra esporte, e ser acrescentado, a palavra exercício, na idéia de atividades motoras, atividades físicas de um modo geral. Com isto nós resgatamos, mais ainda, essa idéia de Educação Física e Esporte como dois fenômenos distintos.

Baseado também em alguns desses argumentos, nossa Escola parte para o oferecimento de dois cursos diferenciados, sendo que, para o de Educação Física, em especial, foi necessário adotar um determinado modelo. $O$ que inicialmente nos chamou a atenção foi o fato de não haver como fugir do oferecimento do Bacharelado em Educação Física; se nossa Escola nāo oferecer tal curso não sobreviverá no meio acadêmico. Quero dizer, não entendo na Universidade uma Unidade que não oferece o Curso de Bacharelado e só oferece o Curso de Licenciatura. Caberia aqui para nós uma outra decisão: Como é que fazemos isso?

A própria Universidade de São Paulo nos apresenta vários modelos. Poderíamos fazer um núcleo comum em Educação Física e em determinado momento o aluno iria optar pelo Bacharelado ou pela Licenciatura. Esse modelo, em várias unidades da Universidade de São Paulo, não tem mostrado a sua eficácia pois se dá um privilégio muito grande para o Bacharelado e uma ênfase menor para a Licenciatura. Por exemplo, num curso como o de Química, os alunos estudam muito mais Química quando fazem o Bacharelado em Química, enquanto que no curso de Licenciatura em Química estuda-se menos Química e tem-se como diferenciação uma preparação para a atuação junto à escolarização representada meramente pelas Disciplinas: Introdução aos Estudos da Educação, Psicologia da Educação, Estrutura e Funcionamento do Ensino de Primeiro e Segundo Graus, Didática, e Prática de Ensino. Nós não entendemos a preparação desses dois profissionais assim bifurcada. Em outro modelo, Bacharelado e Licenciatura, representam dois Cursos independentes e distintos. $O$ aluno ingressa na Universidade só para fazer a Licenciatura. Neste caso, mesmo assim apresentam-se situações onde novamente pode ser observado o menosprezo dado ao curso de Licenciatura. Em muitos casos, o Curso de Bacharelado é mais privilegiado e a Licenciatura é algo que ocorre circunstancialmente, inclusive deixando-se a responsabilidade da preparação do professor somente para a Faculdade de Educação. Dessa forma, por exemplo, o aluno torna-se Bacharel em Química, e depois, somente com aquelas "disciplinas pedagógicas", torna-se professor.

O modelo da Escola de Educação Física não deve ser entendido como algo equivalente ao antigo modelo $3+1$ (três mais um), onde alguém cursava três anos de alguma coisa e depois mais um ano de complementação pedagógica e tornava-se professor. A nossa opção foi inclusive uma decisão política- 
acadêmica, ao termos o Bacharelado em Educação Física como pré-requisito, na idéia de que alguém vai ensinar alguma "coisa" na escola de primeiro e segundo graus sabendo tudo sobre essa "coisa". A idéia seguinte: eu faço o Bacharelado em Educação Física e, uma vez tendo este Bacharelado eu agora quero assumir um compromisso com a escolarização, ou quero me adequar à situação econômica atual e ter meu emprego assegurado na instituição escola. Seria a opção de fazer quatro anos de Bacharelado e mais um ano de Licenciatura. Não simplesmente uma complementação para ser professor, mas algo importante, algo bastante refletido. A nossa idéia é que, após o Bacharelado, o aluno vai "comer, beber, dormir e sonhar escolarização", se quiser ir trabalhar na Escola. E nãó simplesmente, eu vou fazer a Licenciatura porque será um reforço a mais no meu salário e uma seguránça maior a nível empregatício. Então, o nosso modelo a ser implementado parte daí, parte de alguém que faz 4 anos de Educação Física - o Bacharelado - e agora, se quer ensinar Educação Física na escola, vai cursar a Licenciatura e vai então entender de escolarização.

No entanto, nós estamos visualizando vários problemas em relação a esse modelo. Problemas que extrapolam a vida desta Escola de Educaçáo Física. Por exemplo, direi rapidamente o que nós entendemos por esta parte da Licenciatura. Nós pensamos em temas a serem discutidos e estudados pelos alunos; algumas disciplinas específicas que caracterizam a função do profissional-professor, e aqui nós listamos aqueles temas a serem desenvolvidos. Eu queria ver um professor atuando na escola entendendo, entre alguns temas, de História da Educação Escolarizada, de Antropologia da Educação Escolarizada, de Sociologia da Educação Escolarizada, de Economia da Educação Escolarizada, de Política da Educação Escolarizada, e de Administração da Educação Escolarizada. E, logicamente, no âmbito desta Universidade, a responsabilidade do desenvolvimento desses temas nâo caberia a esta Escola de Educação Física, que deve ter um objeto de estudo específico, independente e diferenciado do objeto de estudo específico da Educação. Então nós fomos, logicamente, pedir este auxúlio à Faculdade de Educação. Agora, só lembrando que, somando-se simplesmente os conteúdos de Filosofia, de Psicologia, ou de Antropologia, etc., não se tem ao final um professor. A idéia foi bem outra, e nós fomos antes disso, por exemplo, ainda no Curso de Bacharelado em Educação Física, solicitar para a unidade mãe uma Disciplina sobre elementos de Antropologia. Vejam o quanto isso faz com que a Escola de Educação Física não fique isolada, pois ela busca na idéia de universidade, o respaldo de outras Unidades. Então, imaginem só a seqüếncia: elementos de Antropologia, elementos de Antropologia e Educação Física - no Bacharelado, e, se quero ensinar Educação Física no primeiro e segundo graus, estudo também elementos de Antropologia relacionados com Escolarização e Educação Física enquanto componente curricular. No entanto é bem complexa e ampla essa intenção; e de certa forma, nós não encontramos, para grande parte dessas pretensões, um respaldo das Unidades universitárias. Por exemplo, o Departamento de Sociologia não pode oferecer uma Disciplina "Elementos de Sociologia", ou por falta de recursos humanos, ou por falta de interesse, ou por algum outro problema político. Então, o que acontece com a Educação Física? Ela quer se expandir e não consegue por várias razões. Então ela passa, no meu ponto de vista, a camuflar, distorcer, e a enfraquecer o processo de preparação profissional. Nós vamos então, ao tratar da Disciplina "Dimensões Antropológicas da Educação Física", no Curso de Bacharelado, no qual não teremos a Disciplina "Elementos de Antropologia", passar, num primeiro momento daquela Disciplina, a falar sobre Antropologia, e depois tentaremos ver as relações entre Antropologia e Educação Física.

Da mesma forma a Faculdade de Educação, em dois momentos distintos, coloca de uma forma bem diplomática, ou não querendo causar conflito que, "se nós da Faculdade de Educação não estamos conseguindo reformular a Licenciatura, quem são vocês da Educação Física para propor isso"? Esta proposta da Escola de Educação Física, aqui sendo apresentada, foi, em determinada ocasião, muito apreciada e teve o respaldo de autoridades universitárias, pois ela refletia o seguinte: Vamos parar de brincar de Licenciatura; vamos repensar urgentemente a Licenciatura. Mas a Faculdade de Educação não teve, não digo competência, mas momento político para nos dar respaldo. No entanto, parece que nosso modelo teve alguma implicação: nós vamos ter no dia 13 de novembro, aqui na Universidade de São Paulo, um colóquio sobre Licenciatura e no dia 14 de dezembro, um fórum sobre Licenciatura com a idéia de tentar estabelecer diretrizes para a problemática relacionada com a preparação de professores. 
Entendemos também, nesta Escola de Educação Física, que não temos a pretensão que este nosso modelo seja o modelo que resolva os problemas especificos de todo o país. Vejo claramente momentos diferenciados, e dependentes de várias circunstâncias. Recebemos algumas críticas, sendo uma delas assim expressa: Espera um pouco, um professor vai sair da Universidade de São Paulo, do curso de Educação Física após 5 anos de estudol Que loucura é esta? Tal crítica é justificada com a comparação entre Licenciaturas em outras áreas, com a consideração da necessidade de estímulo para a profissão de professor, e com o fato de que o professor está ganhando mal. Acredito que tudo isso foi considerado em várias instâncias e discussões pertinentes, e tive uma resposta bem clara a essas preocupações: Ora, quem quiser se formar professor em Educação Física, em uma instituição fora da Universidade de São Paulo, tem toda liberdade. Quer dizer, alguém pode estudar em Santo André, em Guarulhos, em Santo Amaro; mas quem quiser vir para cá, tem claro este nosso modelo. Existe local para todos. Porém, a Universidade de São Paulo está preocupada em tentar formar e preparar um professor da melhor forma possível. Vários modelos poderão aparecer; nós estamos centrando esforços neste modelo.

E a intenção nossa é valorizar ao máximo a profissão de Professor de Educação Física. A idéia É investir nesse bom professor, cuja preparação profissional especifica não é só um apêndice, uma complementação; não representa simplesmente 4 anos de Bacharelado mais um ano de Licenciatura. Vejo que isso é dinâmico, é um processo de mudança e, uma vez que nós entendemos o processo, estamos prontos para as adaptaçōes, se necessárias. Uma vez que a Faculdade de Educação ou alguns segmentos responsáveis pelos problemas da escolarização, tenham claro que aquilo que nos interessa, do ponto de vista profissional, é o professor, nós teremos que, daqui para a frente, formar alguém para ser especificamente professor. E ser professor significa entender muito bem dos problemas de escolarização. Eu diria que, como foi colocado ontem sobre a idéia da habilitação para o magistério no segundo grau, não tivemos forças ou vontade política, enquanto organização social, para discutir claramente a farsa atual, consideradas algumas situaçōes ainda caóticas da escolarização, dessa habilitação, que acredito, teve sua importância em um momento histórico no passado, hoje não mais, mas continua ar. Somente quando tivermos bem claro que ser professor é a profissão e o principal, e o quê vai ser ensinado é secundário, daí sim estaremos propensos e prontos para reverter essa situação. Em primeiro lugar, preparamos o professor; agora o quê ele vai ensinar é secundário: se Educação Física, ou Geografia, ou História, etc. Hoje ocorre o contrário: Primeiro eu entendo muito bem da minha área específica, e se eu quero ensinar, ou entender de escola, é secundário.

Assim, como participante desta mesa redonda, passo estas informaçooes, passo estas dificuldades que nós estamos vivenciando. Dificuldades até compreensíveis do ponto de vista de entendimento da própria Universidade. Agora, se não for possível andarmos juntos, lado a lado, contando também com as pernas dos outros, nós vamos ter que andar somente com nossas próprias pernas. E vejo que esta Escola de Educação Física, daqui para a frente, terá que se preocupar muito mais, infelizmente, com a preparação interna de nossos recursos bumanos, no sentido de suprir a falta de colaboração de outras Unidades universitárias; deveremos estudar muito mais ainda, em relação ao que conhecemos hoje, para garantir uma qualidade de ensino, e conseqüente preparação profissional, dignas desta Universidade de São Paulo. 